e ISSN: $2645-9248 \quad$ Journal homepage: www.jidhealth.com

Case Report Article

\title{
Emphysematous epididymo-orchitis with involvement of the prostate, seminal vesicles, and the scrotum: a case report
}

\author{
Atif Abdulhamid Katib ${ }^{*}$
}

\begin{abstract}
Emphysematous epididymo-orchitis is a rare clinical entity. Up until July 2020, only 9 cases have been reported in PubMed and Scopus platforms, one of which also had scrotal involvement. Therefore, we are reporting the second case with prostate, seminal vesicle, and scrotal involvement. The condition represents an aggressive form of infection caused by gas-forming microbes. The radiological detection of air within the organs involved in the characteristic diagnostic sign. The case we are reporting is a 47 years old diabetic, chronic renal failure patient on regular hemodialysis who had a fulminant emphysematous infection in the left testis, epididymis, spermatic cord, the prostate, seminal vesicles, and the scrotum. Emergency orchiectomy has been carried out. The most significant part of the case is the pictures showing ballooning scrotum and gas bubbles in abnormal anatomical locations.
\end{abstract}

Keywords: Epididymo-Orchitis, Emphysematous Infection, Gas-Forming Organisms, Orchiectomy

\section{Background}

Emphysematous infection of the male genitalia is exceedingly rare. Only six cases have been reported, one of which also had seminal vesicles involvement. We are reporting the second case in the literature that has seminal vesicles involvement. This type of infection is caused by gas-forming microbes such as E. coli, Klebsiella, pseudomonas, or fungi. The characteristic gas bubbles are found in and around the affected organs. The gas consists of nitrogen, hydrogen, oxygen, and carbon dioxide. The pathogenesis of emphysematous infection is poorly understood. It commonly occurs in diabetics, elderly, transplant recipients, patients with neurogenic bladder, and those with urinary tract obstruction. Clinically, emphysematous infections are serious infections that fulminate rapidly and require urgent surgical intervention.

\section{Case report}

A 47-year-old man presented to the emergency department complaining of scrotal pain, scrotal wall maceration with crepitation, and high fever $(38.4 \mathrm{C})$ for two days. Upon presentation, he was in septic shock with leukocytosis, anemia, and high blood sugar.

His anamnesis showed poor background. He has had a chronic renal failure (CRF) on regular hemodialysis, diabetes

*Correspondence: atifkatib@gmail.com

${ }^{1}$ Department of Urology/Andrology, King Abdul-Aziz Hospital, Makkah, Saudi Arabia

Full list of author information is available at the end of the article mellitus (DM) type 2 on insulin for 20 years, three amputated toes, and obesity. Soon after admission, his condition turned sharply to become life-threatening that necessitates urgent investigations and surgery. Ultrasonic examination $(\mathrm{u} / \mathrm{s})$ has shown ballooned left scrotum (fig.1). Computer tomography scan (CT), too, has revealed gas in the scrotum (fig.2), and within the confinements of the testis, spermatic cord (fig.3), seminal vesicles (fig.4), and the prostate (fig.5). Operatively, no tissue putrefaction or necrotizing fasciitis found.

When we opened the tunica albuginea, we found no much of recognized testicular tissues, as they have been eaten up by the aggressive infection. Based on the best of our experience and intuition, we decided to excise the testis from the highest possible level near the internal ring and to spare the scrotum. We believed that removing the prostate and seminal vesicles would do more harm than good, and they could be treated conservatively. Nevertheless, exploration of the contra-lateral hemiscrotum has shown otherwise normal testis. On close follow up, the scrotum caught up and survived. Histopathology revealed acute inflammation of the testis, epididymis, and cord with areas of necrosis and thrombosis of veins. Astonishingly, the blood culture came negative. The patient did well on the empirical combination of Tazocin (Piperacillin/ tazobactam) plus Clindamycin antibiotics. He had a smooth postoperative course and discharged after recovery. A follow-up CT in a month showed the disappearance of the gas bubbles from the scrotum, seminal vesicle, and prostate. 


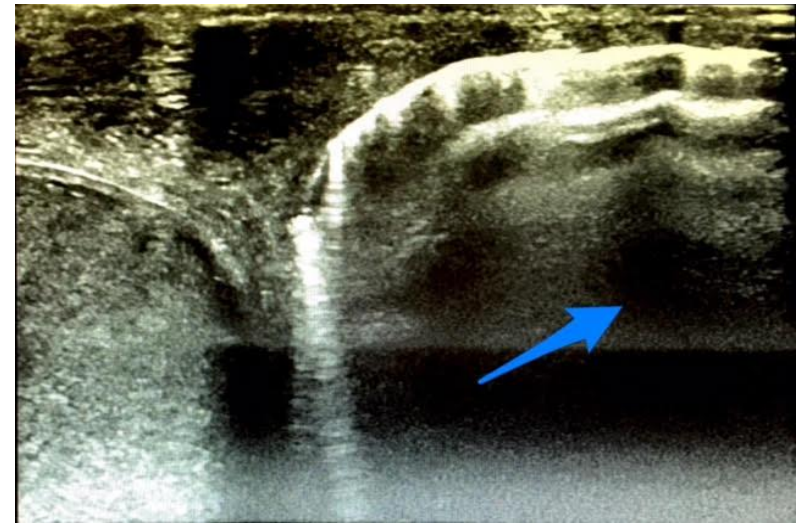

Figure 1: Ultrasound image showing the scrotum filled with air

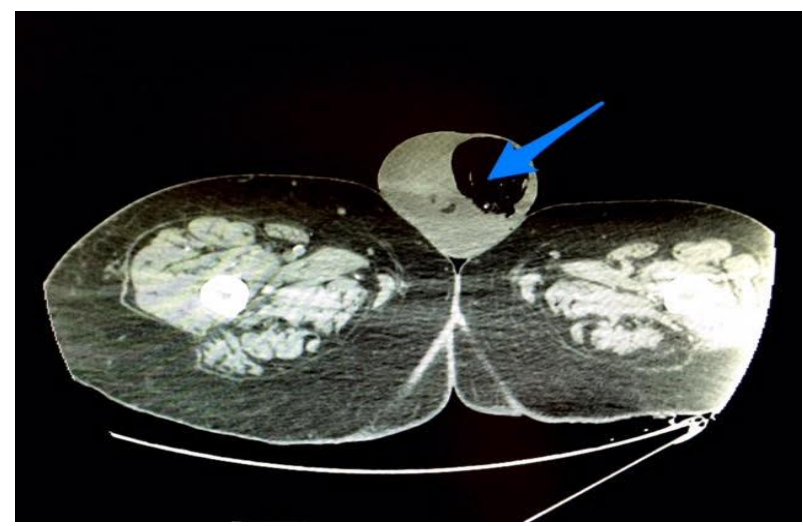

Figure 2: CT scan, cross-sectional view, showing a massive amount of air ballooning the lt. hemiscrotum

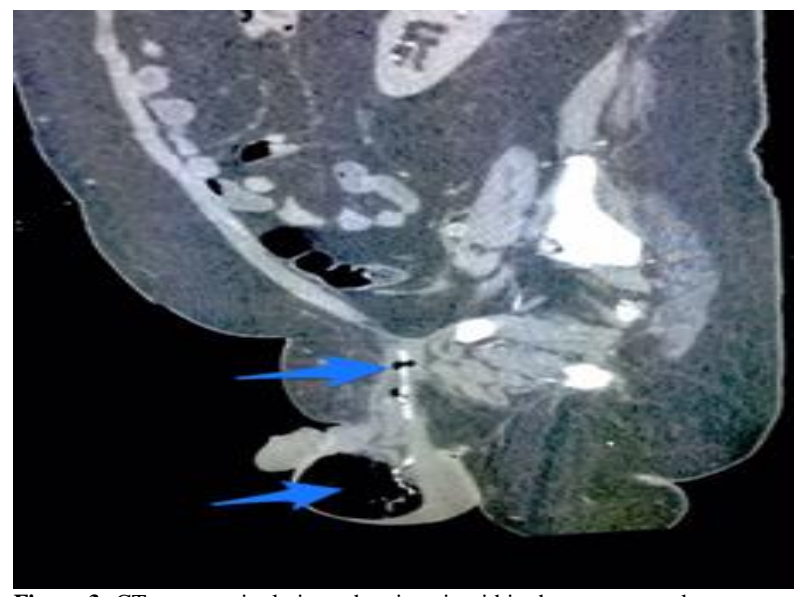

Figure 3: CT scan, sagittal view, showing air within the scrotum and the spermatic cord

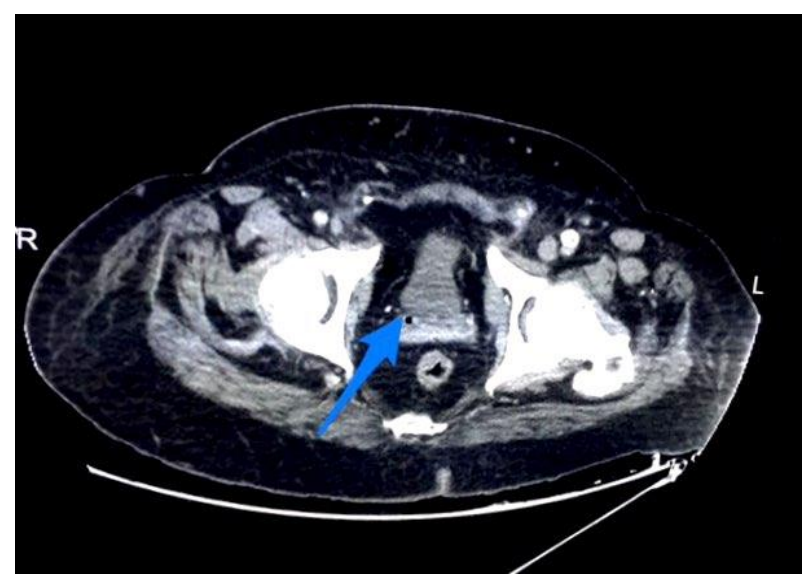

Figure 4: CT cross-sectional view, showing air in the seminal vesicles

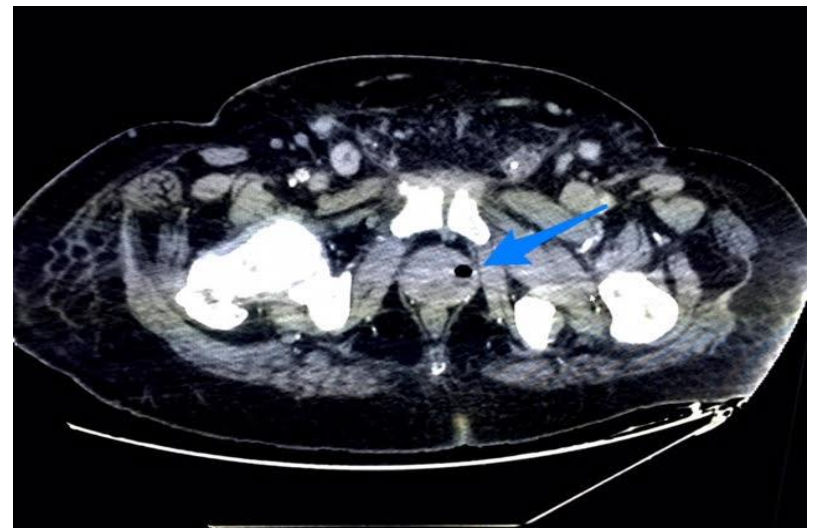

Figure 5: CT cross-sectional view, showing air in the prostate gland

Discussion

Emphysematous infection of the testis is extremely rare [1]. One of the reported cases had seminal vesicle involvement due to a fistula developed secondary to sigmoid diverticulitis [2]. However, the infection in the case we are reporting had spread in no time, probably due to poor body immunity. Although the scrotum looks similar to Fournier's gangrene case series, we have reported $[3,4]$, pneumoscrotum is substantially different in this case. It doesn`t smell bad, with no spread to surrounding structures such as perineum, penis, or the right hemiscrotum. The rarity of the case is ascribed to its infrequent occurrence. The ambiguity lies in explaining the involvement of various organs supplied by different arteries. That is to say, the blood supply of testes from the aorta; and the prostate and seminal vesicles from internal iliac arteries, whereas the scrotal wall receives blood supply from the internal and external pudendal branches of the external iliac artery. The direct spread of infection could explain the transmission of infection among adjacent organs, especially weak body defense. There is no much information, let alone guidelines, over the best way to treat such an intricate condition. Follow-up CT has revealed no more gas bubbles. The scrotal condition has improved gradually. Confidently, the differential diagnosis of acute scrotum could be zoomed down to emphysematous infection of the testis by the colossal amount of air that appeared on ultrasonography and CT. On ultrasonic examination, air appears as a bright, highly reflective tissue interface of the testis. CT is considered the diagnostic modality of choice, as it demonstrates air within and around the testis, cord, prostate, and seminal vesicles. On CT, air appears as hypodense foci or patchy areas of very low Hounsfield unit $(-1000 \mathrm{HU})$. The controversies surrounding requesting magnetic resonance image (MRI) in this setting, we have the intuition that MRI does confirm the presence of air in the testis substance but doesn`t add up further information. Therefore, we believe that MRI, in this case, is not recommended as it, unnecessarily, consumes time, and delays the emergency operation.

\section{Conclusion}

Emphysematous acute epididymo-orchitis is a rare clinical entity. It should be thought of in frail men with significant comorbidity presented to the casualty with a febrile cute scrotal condition. Radiologic evidence of air in the affected tissues is unmistakable. Life-saving medical and surgical management is required. 


\section{Abbreviations}

CRF: Chronic Renal Failure; DM: Diabetes Mellitus; CT: Computer Tomography Scan; US: Ultrasonic examination (u/s); HU: Hounsfield unit; MRI: Magnetic Resonance Image

Declarations

Acknowledgment

None

\section{Funding}

The author received no financial support for the research, authorship, and/or publication of this article.

\section{Availability of data and materials}

Data will be available by emailing atifkatib@gmail.com

\section{Authors' contribution}

Atif Abdulhamid Katib (AAK) is the principal investigator of this manuscript (Case Report). AAK is the responsible author for the study concept, design, writing, reviewing, editing, and approving the manuscript in its final form. AAK has read and approved the final manuscript.

Ethics approval and consent to participate We conducted the research following the Declaration of Helsinki. However, Case Report Articles need no ethics committee approval.

Consent for publication

Not applicable

\section{Competing interest}

The author declares that he has no competing interests.

\section{Open Access}

This article is distributed under the terms of the Creative Commons $\begin{array}{llll}\text { Attribution } & 4.0 & \text { International }\end{array}$ (http://creativecommons.org/licenses/by/4.0/), which permits unrestricted use, distribution, and reproduction in any medium, provided you give appropriate credit to the original author(s) and the source, provide a link to the Creative Commons license, and indicate if changes were made. The Creative Commons Public Domain Dedication waiver (http://creativecommons.org/publicdomain/zero/1.0/) applies to the data made available in this article, unless otherwise stated.

Author details

${ }^{1}$ Department of Urology/Andrology, King Abdul-Aziz Hospital, Makkah, Saudi Arabia

\section{Article Info}

Received: 10 August 2020

Accepted: 16 August 2020

Published: 21 August 2020

\section{References}

1. Mathur A, Manish A, Maletha M, Luthra NB. Emphysematous epididymo-orchitis: A rare entity. Indian J Urol. 2011;27(3):399400. DOI: 10.4103/0970-1591.85447.

2. Coulier B, Ramboux A, Maldague P. Emphysematous epididymitis as presentation of unusual seminal vesicle fistula secondary to sigmoid diverticulitis: case report. Abdom Imaging 2004;30: 113-116. https://doi.org/10.1007/s00261-004-0216-1

3. Katib A, Al-Adawi M, Dakkak B, Bakhsh A. A three-year review of the management of Fournier's gangrene presented in a single Saudi Arabian institute. Cent European J Urol. 2013;66(3):331334. doi:10.5173/ceju.2013.03. art22

4. Balani A, Hegde R, Dey A. Intratesticular and scrotal wall air: Emphysematous epididymo-orchitis or Fournier's gangrene: A dilemma. Indian J Radiol Imaging $2015 ; 25(1): 74$ 